\title{
Laser photo-thermal therapy of epithelial carcinoma using pterin-6-carboxylic acid conjugated gold nanoparticles
}

\author{
Linda Bertel $^{1,2} \cdot$ Stelia Carolina Mendez-Sanchez ${ }^{3} \cdot$ Fernando Martínez-Ortega $^{1,2}(\mathbb{C}$
}

Received: 10 June 2021 / Accepted: 19 October 2021 / Published online: 8 November 2021

(c) The Author(s), under exclusive licence to European Photochemistry Association, European Society for Photobiology 2021

\begin{abstract}
Gold nanoparticles functionalized with folic acid toward the internalization into cancer cells have received considerable attention recently. Folic acid is recognized by folate receptors, which are overexpressed in several cancer cells; it is limited in normal cells. In this work, pterin-6-carboxylic acid is proposed as an agonist of folic acid since the pterin-6-carboxylic acid structure has a pterin moiety, the same as folic acid that is recognized by the folate receptor. Here a simple photochemical synthesis of gold nanoparticles functionalized with pterin-6-carboxylic acid is studied. These conjugates were used to cause photothermal damage of HeLa cells irradiating with a diode laser of $808 \mathrm{~nm}$. Pterin-6-carboxylic acid-conjugated gold nanoparticles caused the death of the cell after near-infrared irradiation, dose-dependently. These results indicate a possible internalization of AuNPs via folate receptor-mediated endocytosis due to the recognition or interaction between the folate receptors of HeLa cells and pterin, P6CA.
\end{abstract}

\section{Graphical abstract}
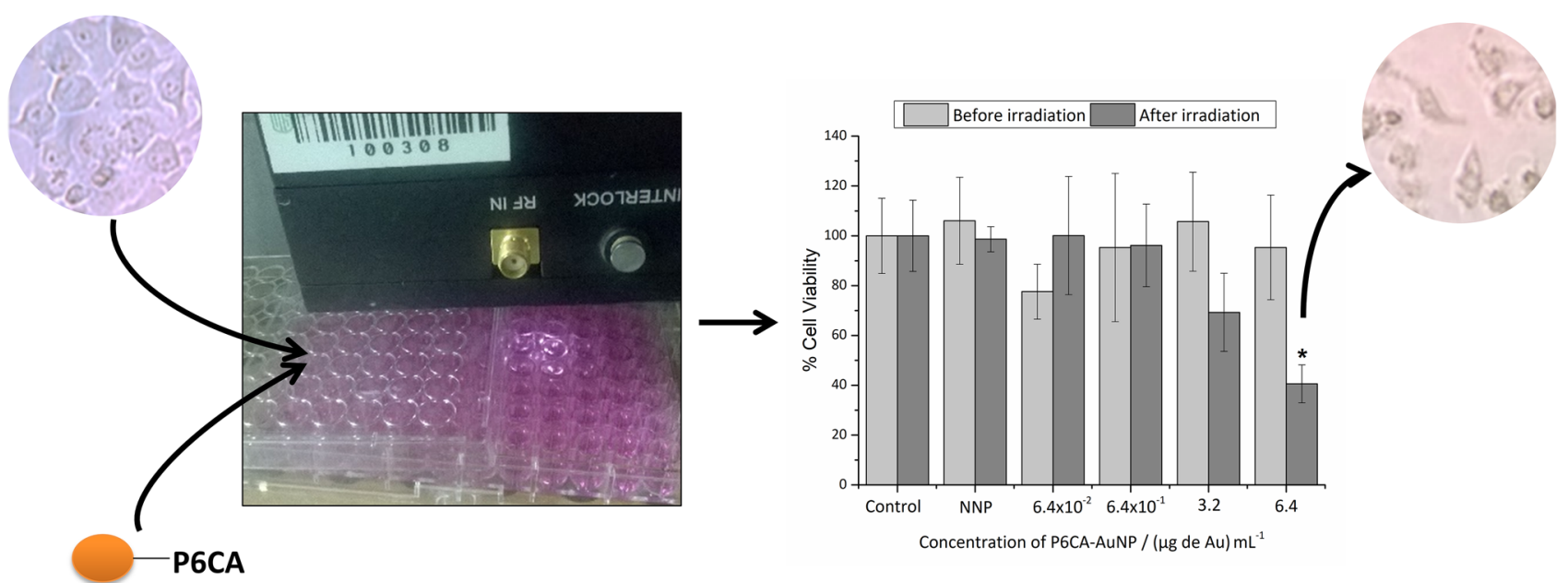

$=$ Gold Nanoparticle<smiles>CC(C)(C)OC#P</smiles>

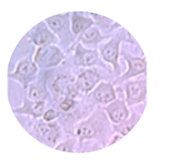

$=$ HeLa cells

Linda Bertel

linda.bertel@correo.uis.edu.co

$\triangle$ Fernando Martínez-Ortega

fmartine@uis.edu.co

Extended author information available on the last page of the article 


\section{Introduction}

The photochemical methodologies for synthesizing gold nanoparticles (AuNPs) permit reduced preparation time and produced particles with polygonal [1], spherical [2], and like-rods [3] shapes. Huang et al. developed a simple photochemical synthesis of AuNPs mixing hydrogen tetrachloroaurate with sodium oxalate under the illumination of a mercury lamp $\left(\lambda_{\max }=306 \mathrm{~nm}\right)$ for more than $10 \mathrm{~min}$. 1 While Rodríguez-Torres et al. report a photochemical synthesis of AuNPs functionalized with heparin using UV black-light lamp irradiation $\left(\lambda_{\max }=366 \mathrm{~nm}\right) 0.4$ HeparinAuNPs are good candidates for biological applications, e.g., for imaging of metastatic cancer cells and apoptosis [5], as they are biocompatible and have a good affinity for various biomolecules [4]. This study showed that AuNPs functionalized by a photochemical procedure could be interesting for future biological applications.

The folic acid (FA) or vitamin B9, also known as folate, is a biomolecule that has received special attention as a targeting ligand for cancer cells, predominantly for ovarian cancers that overexpress folate receptors, since FA binds to folate receptor with a high affinity $\left(\mathrm{Ka} \approx 10^{10} \mathrm{M}^{-1}\right)$ [6-8]. Folate receptor is overexpressed on a large variety of epithelial cancer cells (cancer of the ovary, cervix, endometrium, lung, kidney, brain, head, and neck). However, it has limited expression on normal cells, which is crucial for its application in selective targeting for cancer cells. 6 In cancer applications, where the FA-folate receptor interaction is studied, it is essential to choose an appropriate cell line [9]. In this sense, Siwowska et al. used the Western Blot technique to determine relative FR-expression levels of human cancer cells lines, including cervical (HeLa, KB, KB-V1), ovarian (IGROV-1, SKOV-3, SKOV-3.ip), choriocarcinoma (JAR, BeWo), and endometrial (EFE184) tumour cells. Comparisons of FR-expression results revealed the following sequence: KB $>$ KB-V1 $>$ SKOV-3. ip $>$ IGROV-1 $>$ HeLa $\approx$ SKOV-3 $\approx$ JAR $>$ BeWo $>$ EFE184 [9].

FA functionalized nanomaterials and nanocarriers have been reported in diagnostic [6, 8, 10-12] and treatment [13-15] applications. Bellotti et al. developed terpolymerbased nanocapsules loaded with DNA functionalized with FA for the targeted delivery of nucleic acids to cancer cells. They showed that the nanocapsules functionalized with FA were directed and internalized in HeLa cells with overexpression of folate receptors [16. FA was anchored to AuNPs to reach the internalization of these nanoparticles mediated by folate receptors into cancer cells [17]. Li et al. synthesized AuNPs functionalized with FA (FA-AuNPs) to treat HeLa cells. They observed that FA-AuNPs were internalized through an ICP-MS analysis [18]. Zhang et al. modified AuNPs with glutathione (GSH) to form GSHcapped AuNPs, posteriorly conjugated with FA. This system FA-GSH-AuNPs allowed the detection of HeLa cells with a detection limit of $10^{2}$ cells $/ \mathrm{mL}$ [19].

Metal nanoparticles have unique properties that allow them to act in photothermal cancer therapy. AuNPs exhibit strong absorption in the visible region of the electromagnetic spectrum, called surface plasmon absorption (SPA). These AuNPs can convert efficiently absorbed radiation into heat [20, 21]. For example, gold nanorods (AuNRs) functionalized with FA (FA-AuNRs) have an uptake rate on the order of few minutes in the KB cells. These KB cells treated with FA-AuNRs were irradiated for $81 \mathrm{~s}$ with a tightly focused continuous-wave (cw) laser beamat $765 \mathrm{~nm}$, and cells experienced photothermal damage after irradiation at laser powers as low as $6 \mathrm{~mW}$ (mean power density of $388.8 \mathrm{~W} / \mathrm{cm}^{2}$ ) [22].

Chen et al. discovered that the folate receptor present affinity for the pterin group of FA [23]. Blach et al. tested FA-AuNP and gold nanoparticles functionalized with P6CA (P6CA-AuNP) in the photothermal therapy of HeLa cells and normal human endocervical cells, using an $808 \mathrm{~nm}$ NIR laser with $800 \mathrm{~mW}$ of power during $10 \mathrm{~min}$ [24]. They found that for 4 and $12 \mathrm{~h}$ treatment time, the cell viability for FA-AuNPs decreased in all the concentrations evaluated, while for P6CA-AuNP, there was a decrease in cell viability of $10 \%$ and $17 \%$ for 4 and $12 \mathrm{~h}$ treatment time, respectively, at the highest concentration tested $(500 \mu \mathrm{M})$.

This work proposed the potential use of pterin-6-carboxylic acid (P6CA, chemical structure like the FA) as a target ligand for cancer photothermal therapy. Here, a simple one-step photochemical synthesis of P6CA-AuNPs was developed, without surfactants and long reaction times, for photothermal therapy of HeLa cells using $808 \mathrm{~nm}$ NIR laser for irradiation during $5 \mathrm{~min}$ at $800 \mathrm{~mW}$. The results show that AuNPs functionalized with a molecule with a pterin group can internalize and cause cell damage to cancer cells like their correspondent FA-AuNPs in the presence of near-infrared (NIR) radiation [15].

\section{Experimental}

\subsection{Materials}

P6CA, hydrogen tetrachloroaurate (III) trihydrate (HAuCl4.3H2O), Bromure of 3-(4,5- dimetiltiazol-2-yl)2,5-diphenyl tetrazole (MTT) and Eagle's Minimum Essential Medium (EMEM) were obtained from MERCK. These chemicals were of analytical grade. 


\subsection{Synthesis of gold nanoparticles and functionalization with P6CA}

Gold nanoparticles functionalized with P6CA were prepared from an aqueous solution of P6CA ( $5 \mathrm{~m} \mathrm{M}, 336$ $\mu \mathrm{L}$ and $\mathrm{HAuCl}_{4} .3 \mathrm{H}_{2} \mathrm{O}(0.01 \mathrm{M} ; 300 \mu \mathrm{L})$ were mixed with $9.364 \mathrm{~mL}$ of MilliQ water in a photochemical reactor (Ace-Glass model T-121 m), which was wrapped with an aluminium foil. The $\mathrm{pH}$ of the reaction mixture was fixed, adding some drops of $\mathrm{NaOH} 0.1 \mathrm{M}$ to obtain a $\mathrm{pH}=11$. Later, the mixture was irradiated by a UV lamp $\left(\lambda_{\max }=254 \mathrm{~nm}\right)$ for 10,25 and $45 \mathrm{~min}$, under magnetic stirring according to our reported procedure $[15,25]$. A thermostat bath was used to avoid the reaction from overheating. Bath temperature was maintained at $19{ }^{\circ} \mathrm{C}$ during the irradiation. The final P6CA-AuNP dispersion was dialyzed for $8 \mathrm{~h}$ to remove excess free P6CA. Free P6CA decreasing was determined by a reading of maximum absorbance at $364 \mathrm{~nm}$ and a calibration curve of concentrations between 0.01 and $0.25 \mathrm{mM}$. Dialysis was performed under sterile conditions in a laminar flow cabinet. Similarly, an aqueous solution of $\mathrm{HAuCl}_{4} \cdot 3 \mathrm{H}_{2} \mathrm{O}$ $(300 \mu \mathrm{L} ; 0.01 \mathrm{M})$ and $9.7 \mathrm{~mL}$ of MilliQ water were mixed in the photoreactor. Later, this mix was irradiated by the UV lamp with shaking for $45 \mathrm{~min}$. This product is called naked AuNPs (NNP) and is used to make comparisons with P6CA-AuNP.

\subsection{Characterization of P6CA-AuNP}

UV-Vis absorbance spectra recorded using a Shimadzu UV-2401PC spectrophotometer with double-beam were then used to characterize the SPA of nanoparticles. Free P6CA and P6CA-AuNP solutions were analyzed by fluorescence utilizing a Perkin Elmer LS-55 spectrofluorometer. A drop of Free P6CA and P6CA-AuNP were air-dried, and ATRIR spectra were analyzed in a Nicolet FT-IR IS50. A Quanta 650 FEG scanning electron microscope was used to obtain SEM images and energy dispersive X-rays spectroscopy (EDS) elemental analysis of P6CA-AuNP. A Zetasizer Nano ZS90 was used to determine the Zeta potential and size distributions of nanoparticles prepared.

\subsection{Characterization of NNP}

NNP were characterized by UV-Vis absorbance operating a Shimadzu UV-2401PC spectrophotometer with double-beam. SEM images and EDS elemental analysis were obtained using a Quanta 650 FEG scanning electron microscope. Zeta potential and size distributions of nanoparticles were extracted from DLS analysis employing a Zetasizer Nano ZS90.

\subsection{Assays in HeLa cells}

In this work, HeLa cells are used as cancer cells that overexpress folate receptor $[9,16]$ to study the folate receptor-mediated endocytosis of P6CA-AuNPs. HeLa cells in Eagle's Minimum Essential Medium (EMEM) supplemented with $10 \%$ FBS was added in 96 well plates (density of 5000 cells/well) and incubated for $24 \mathrm{~h}$ at $37^{\circ} \mathrm{C}$ with a $5 \% \mathrm{CO}_{2}$ atmosphere. To analyze the relationship between functionalized AuNP concentration and cell viability percentage, cells were treated with different concentrations of P6CA-AuNP $\left(6.4 \times 10^{-2}, 6.4 \times 10^{-1}, 3.2\right.$ y $6.4(\mu \mathrm{g}$ of $\left.\mathrm{Au}) / \mathrm{mL}\right)$ in EMEM, 3 wells for concentration. Meanwhile, a group of cells ( 4 wells) was treated with NNP $(6.4 \mu \mathrm{g}$ of $\mathrm{Au} / \mathrm{mL})$ as a comparison blank. No nanoparticles were added to the four wells used as control. After $48 \mathrm{~h}$ of internalization treatment, cells were illuminated for $5 \mathrm{~min}$ by a diode laser (ThorLabs Newton USA, $808 \mathrm{~nm}$ ) at $800 \mathrm{~mW}$ of power. The control wells were also exposed to light (irradiated control). The distance between the diode and samples was about $2.5 \mathrm{~cm}$. MTT assay was done $12 \mathrm{~h}$ after ended irradiation. Simultaneously, in a different plate, treated and control cells were grown without irradiation. Lastly, the medium culture was discarded, and $200 \mu \mathrm{L}$ of MTT $(500 \mu \mathrm{g} / \mathrm{mL}$ in HBSS $)$ was added to each well. After $3 \mathrm{~h}$ of incubation, the supernatant was removed, and $200 \mu \mathrm{L}$ of DMSO was added to dissolve the crystals formed. Reading absorbance at $550 \mathrm{~nm}$ was performed in a microplate reader, using DMSO as a blank [26].

Data were presented as means \pm SE from at least two independent experiments and compared by analysis of variance (ANOVA) followed by multiple comparison analysis averages, Tukey. Differences at $p<0.05$ were considered statistically significant.

\section{Results and discussion}

Four P6CA/HAuCl $4.3 \mathrm{H}_{2} \mathrm{O}$ molar ratios $(0.44 / 1,0.5 / 1$, $0.56 / 1$, and 0.62/1) were used to evaluate the effect of AuNP growth in the synthesis of P6CA-AuNP. These molar ratios were selected based on previous FA-AuNP synthesis works $[18,25]$. When UV-Vis spectra of products were analyzed, the characteristic SPA band of spherical AuNPs could be observed around $530 \mathrm{~nm}$ for $0.56 / 1$ ratio (see Fig. 1c). This band is not present for the other molar ratios, indicating no formation of nanoparticles is obtained (Fig. 1a, b and d). For molar ratios lower than $0.56 / 1$ is not sufficient to stabilize the clusters formed and therefore agglomerates are formed, as observed by Li et al. in the synthesis of FA-AuNP when testing the FA / HAuCl4 ratio of 0.25/1 [18]. Li et al. also 
Fig. 1 Absorption spectra of the P6CA-AuNP aqueous solution prepared with different molar ratios $\mathrm{P} 6 \mathrm{CA} / \mathrm{HAuCl}_{4} \cdot 3 \mathrm{H}_{2} \mathrm{O}$ : 0.44/1 (a), 0.50/1 (b), 0.56/1 (c), 0.62/1 (d) and different UV irradiation time: 10 (black line), 25 (blue line) and $45 \mathrm{~min}$ (red line)

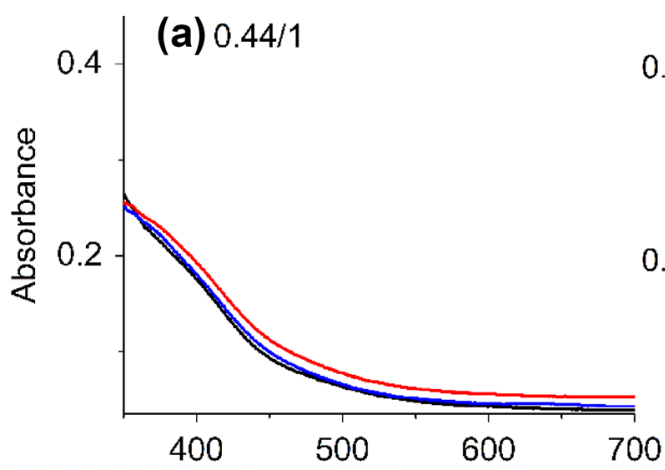

(b) $0.5 / 1$
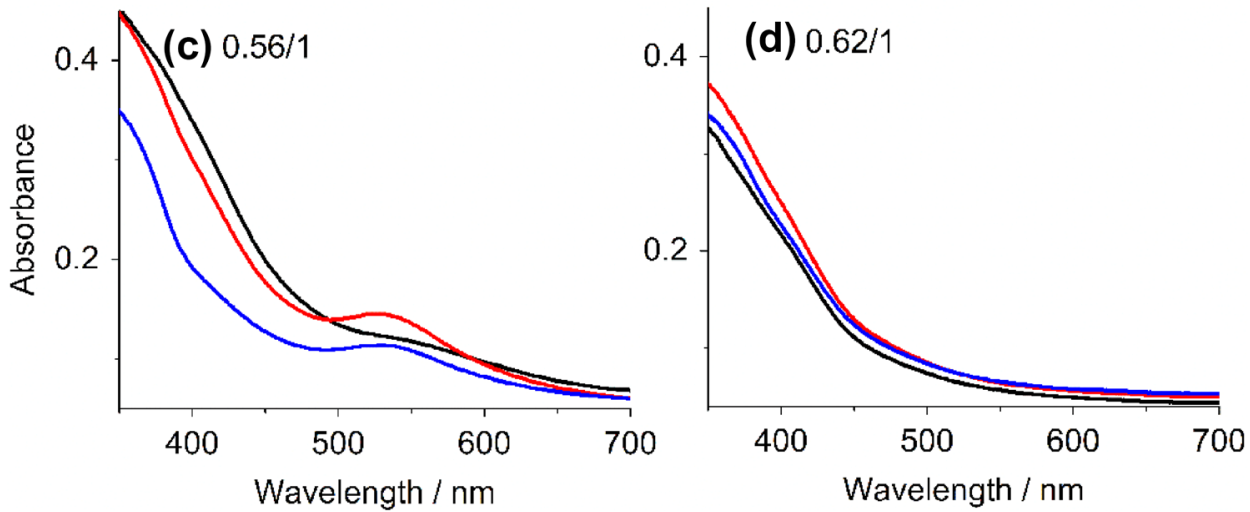

observed that by increasing the molar ratio to $0.61 / 1$ the nanoparticles formed were tiny and irregular in shape. In our case, it is probable that at the $\mathrm{P} 6 \mathrm{CA} / \mathrm{HAuCl}_{4} \cdot 3 \mathrm{H}_{2} \mathrm{O}$ ratio of $0.62 / 1$, AuNPs smaller than $2 \mathrm{~nm}$ are formed, known to have no SPA band [27]. Thus, the molar ratio $0.56 / 1$ was selected as the most indicated for preparing of P6CA-AuNP.

The reaction times were selected based on a previous work of synthesis of FA-AuNP by a photochemical method where irradiation times between 10 and 120 min were tested, and good results were obtained between 10 and $45 \mathrm{~min}$.[25]. $\mathrm{UV}$ irradiation time of the reaction mixture was relevant in the formation of nanoparticles when $\mathrm{P} 6 \mathrm{CA} / \mathrm{HAuCl}_{4} \cdot 3 \mathrm{H}_{2} \mathrm{O}$ ratio was fixed at $0.56 / 1$. Figure $1 \mathrm{c}$ (black) shows no SPA band at $10 \mathrm{~min}$ of irradiation. However, with increasing irradiation time, a better-defined band is obtained. Thus, with 45 min of UV irradiation at $0.56 / 1$ of $\mathrm{P} 6 \mathrm{CA} / \mathrm{HAuC} \mathrm{C}_{4} \cdot 3 \mathrm{H}_{2} \mathrm{O}$ molar ratio, the named $\mathrm{P} 6 \mathrm{CA}-\mathrm{AuNP}$ sample has a welldefined plasmon band (Fig. 1c, red). Consequently, this last sample (P6CA-AuNP) was selected for the following experiments, and its free P6CA was removed through a dialysis process. The difference between the P6CA concentration in the colloidal suspension before and after the dialysis was $\sim 0.01 \mathrm{mM}$, determined by UV-vis spectrum.

SEM images of P6CA-AuNP are presented in Fig. 2a and b. An aggregation seeable of the particles due to the solvent evaporation used for SEM analysis is observed (see Fig. 2a). However, Fig. 2b shows a spherical nanoparticle in the SEM image.
The Z-average size and the polydispersity index (PDI) are extracted from the results of the dynamic light scattering (DLS) technique, using the cumulants analysis. The $\mathrm{Z}$-average size and PDI results were $205.4 \pm 6.5 \mathrm{~nm}$ and $0.563 \pm 0.119$, respectively. The PDI indicates an amplitude of the dispersion of the sizes found. Hence, in DLS analysis, values less than 0.1 are usually associated with monodisperse samples, while values greater than 0.7 are related to polydisperse samples [28]. The histogram of P6CA-AuNPs size (Fig. 3a) suggests the presence of three populations of particles, where the smallest particle population is observed around $88 \mathrm{~nm}$, in agreement with the size observed for the particle in Fig. $2 \mathrm{a}$ and $\mathrm{b}$.

One of the most significant challenges in the synthesis of nanoparticles is the reduction of the polydispersity of their constituent particles to obtain nanomaterials with well-defined properties and applications. However, it must be taken into account that, in reality, nanoparticles are never monodisperse and just as two particles are not identical. Polydispersity determines the general characteristics of nanoparticle size-dependent properties, such as cytotoxicity and the photothermal effect of nanoparticles [29]. Qin et al. found that polydispersity, the deviation of nanoparticle size and shape from the nominal value, significantly influences the heat generation of Gold nanorods, while they have a limited effect on Gold nanospheres [30]. For this reason, various of techniques for separating of nanoparticles of different sizes have been used, such as chromatography, extraction, 

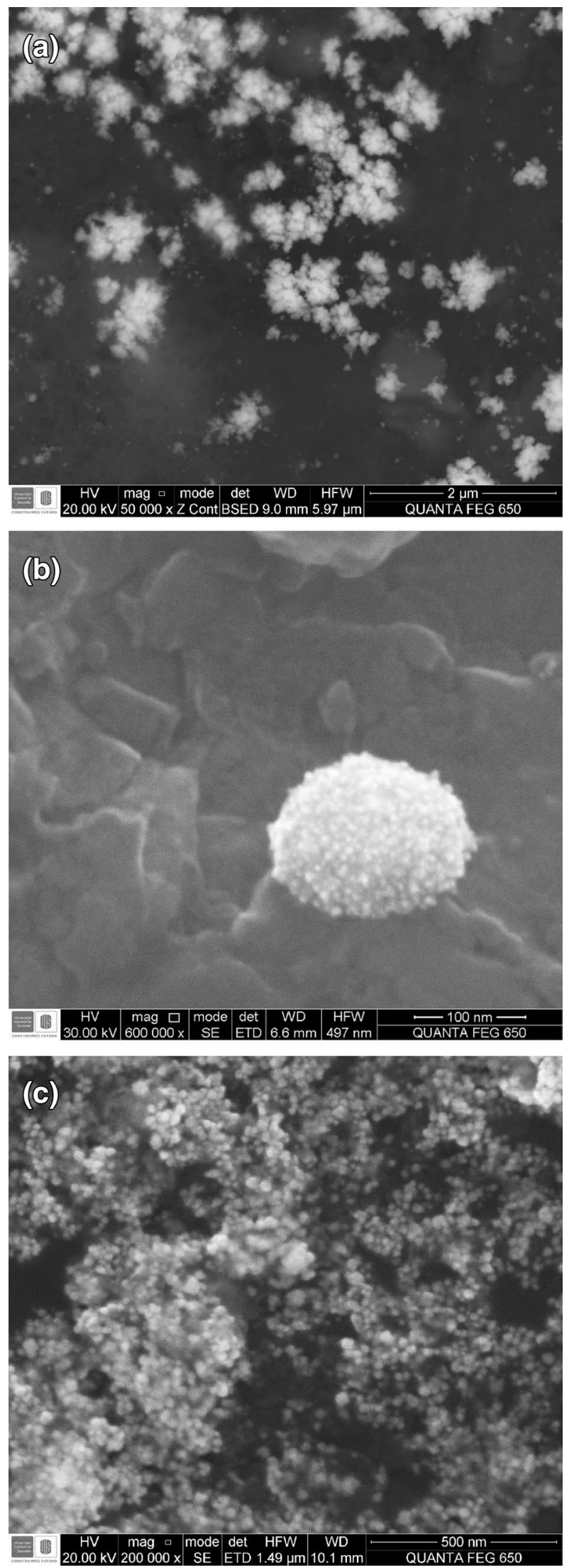

Fig. 2 SEM image of the P6CA-AuNPs of many particles (a), a single P6CA-AuNP (b) and NNP (c)
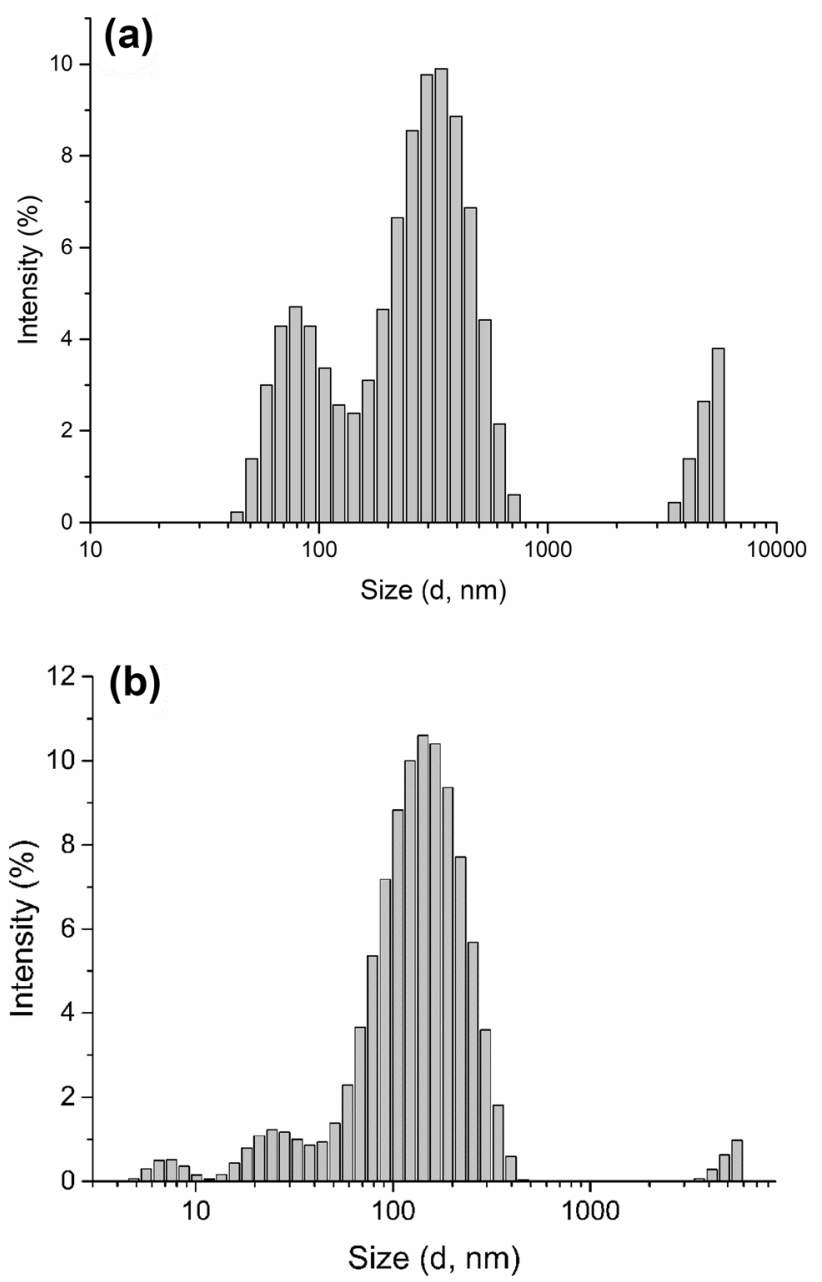

Fig. 3 DLS results for the size distribution by Intensity of P6CAAuNPs (a) and NNP (b)

filtration, density gradient centrifugation, electrophoresis, differential reactivity of differently shaped nanoparticles chemical self-organization, among others. However, we tested this sample of polydisperse nanoparticles to observe the effect of combining different sizes of AuNP in reducing the viability of HeLa cells [29].

The surface charge of P6CA-AuNP synthesized at basic $\mathrm{pH}$ has a group of charges with a maximum peak close to zero, as indicated by its average $\mathrm{Z}$ potential $(-0.014 \pm 0.016 \mathrm{mV})$; that is, the charge density is very low. This result indicates that no forces prevent the particles from approaching each other and forming aggregates over time. However, an advantage of using neutral nanoparticles in this research is that they are preferentially internalized by the cell through the receptor-mediated endocytosis pathway.

Figure 4a shows the EDS analysis of the P6CA-AuNPs, which indicates that nanoparticles are formed mainly of Au. Peaks associated with $\mathrm{Cu}, \mathrm{O}$ and $\mathrm{Al}$ correspond to the support (see Fig. 4c). The Peaks associated with $\mathrm{C}, \mathrm{O}$ and $\mathrm{N}$ are 


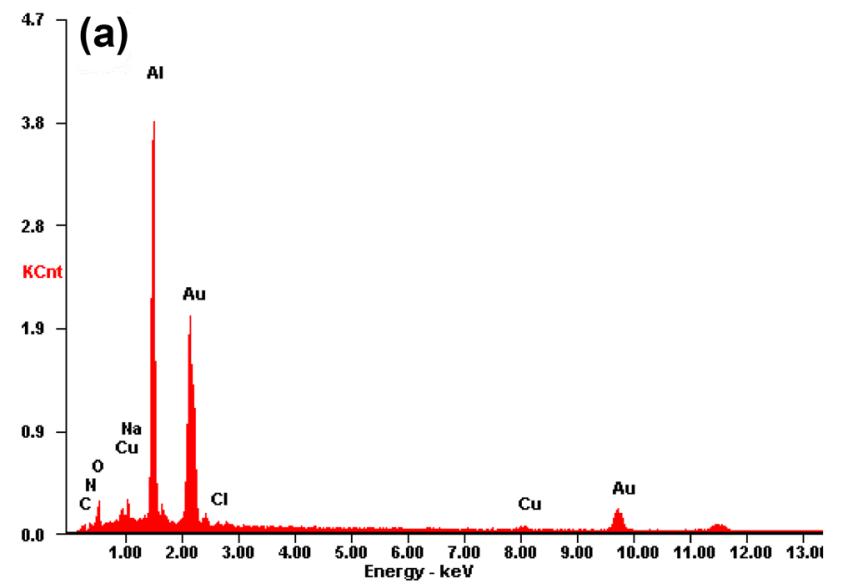

(b)
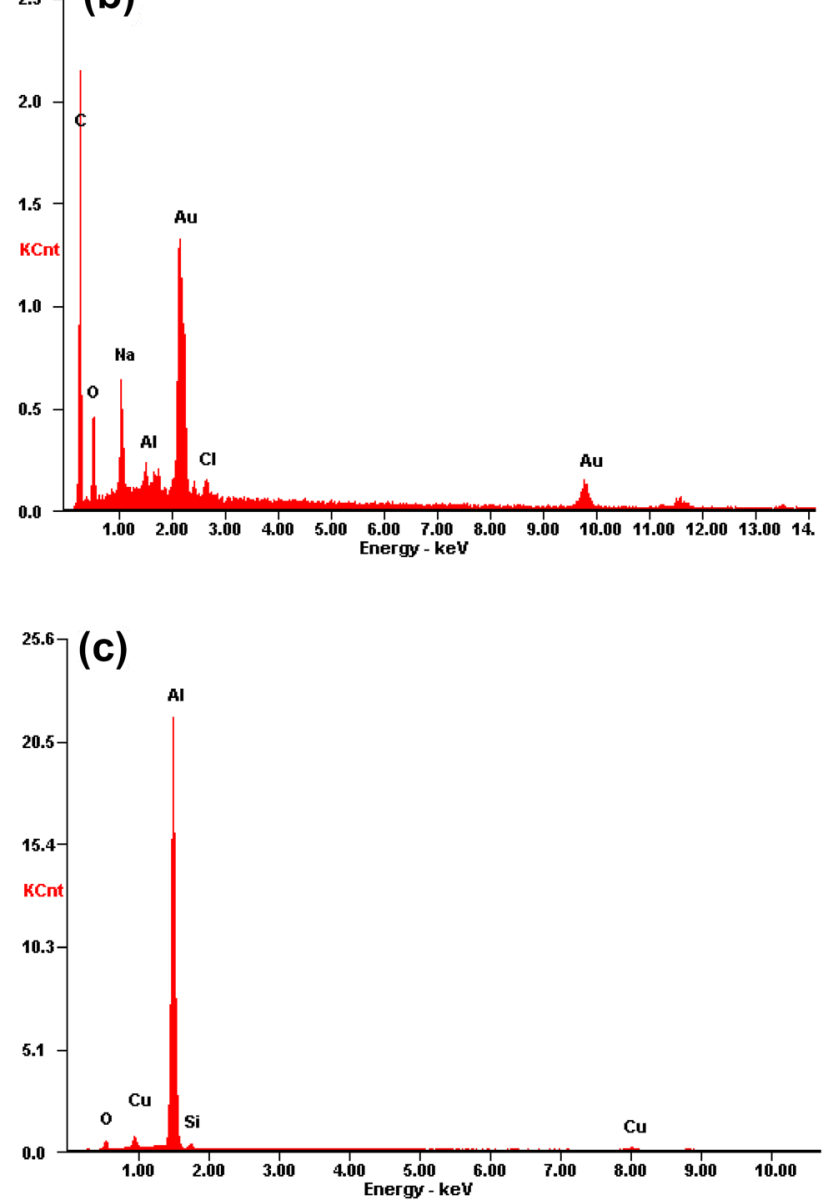

Fig. 4 EDS spectra of P6CA-AuNPs (a), NNP (b) and support (c)

proper to the P6CA structure. $\mathrm{Na}$ is due to the $\mathrm{NaOH}$ used in the synthesis of P6CA-AuNPs. This result indicates that AuNPs are functionalized with P6CA.

ATR-FTIR spectra of the free P6CA and P6CA-AuNP are shown in Fig. 5. Here, significant changes in the bands (between 1300 and $1800 \mathrm{~cm}^{-1}$ ) of P6CA were observed in

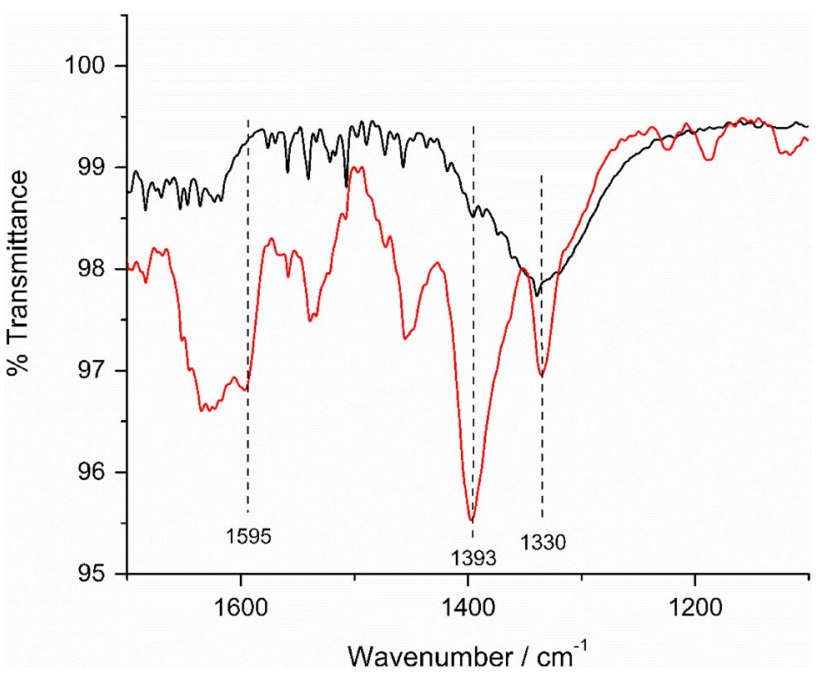

Fig. 5 ATR-FTIR spectra of the free P6CA (red line) and P6CAAuNP (black line)

the P6CA-AuNP spectrum. The carboxylate group vibration band of P6CA $\left(1393 \mathrm{~cm}^{-1}\right)$ was greatly diminished to around $1330 \mathrm{~cm}^{-1}$, and a band widening was also noted. The peak at $1595 \mathrm{~cm}^{-1}$, due to deformation of the amino group, presented a shift to $1620 \mathrm{~cm}^{-1}$ in the P6CA-AuNP spectrum. The displacements of band positions allow suggesting an interaction between Au surface and P6CA molecules through amino and carboxylate groups. These results are agreed with the work of Castillo et al. [23], who founded that AP6C would adsorb on gold nanopillars surface mainly through the nitrogen of the amino group. However, they also found interaction with carboxylate groups and that the AP6C orientation follows a lying down configuration according to surface-enhanced Raman spectroscopy and density functional theory methods.

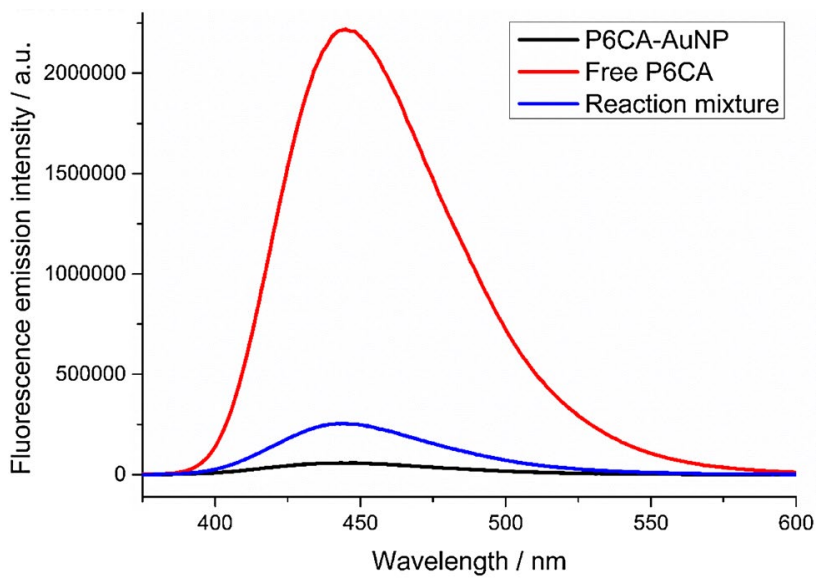

Fig. 6 Fluorescence emission spectra of P6CA-AuNPs aqueous dispersion, free P6CA in type I water and reaction mixture, $\lambda_{\mathrm{ex}}=364 \mathrm{~nm}$ 
Figure 6 shows that the emission intensity of free $\mathrm{P} 6 \mathrm{CA}$ is quenched by the presence of $\mathrm{HAuCl}_{4} \cdot 3 \mathrm{H}_{2} \mathrm{O}$ (for the reaction mixture, spectrum in the blue line, without UV irradiation). However, more significant quenching is observed after de UV irradiation of the reaction mixture (P6CA-AuNP). These results suggest that AuNPs behave as quenchers of the excited state of AP6C molecules due to AuNPs efficiently transport energy. Quenching of the fluorescence emission is mainly attributed to non-radiative decay of the excited state of the fluorophore through electronic states of the metal [31]. Kang et al. found a consensus among researchers about the factor that generates the fluorescence quenching. It is consisting of the reduction of the ratio of radiative to non-radiative decay rate and the quantum yield of the fluorophore produced by the dipole energy around the nanoparticle [32].

Chhabra et al. showed that the fluorescence intensity of the functionalizing molecule depends strongly on its separation distance to AuNPs [33]. They also observed that the larger the size of the AuNPs, the closer the distance (between the fluorophore and nanoparticle) and the more overlap between the emission band of the fluorophore with the AuNP SPA band occurs, the more quenching of the fluorescence intensity happens. When the absorption spectra of P6CA-AuNP and fluorescence emission of P6CA are compared, it can be noted that the SPA band of P6CAAuNP overlaps with the end of the P6CA emission band (see Fig. 7), indicating that the transfer of energy, which causes the phenomenon of quenching, can occur. However, it is also possible that the more significant quenching observed from P6CA-AuNP suspension is due to a closer interaction of AuNP with P6CA molecules.

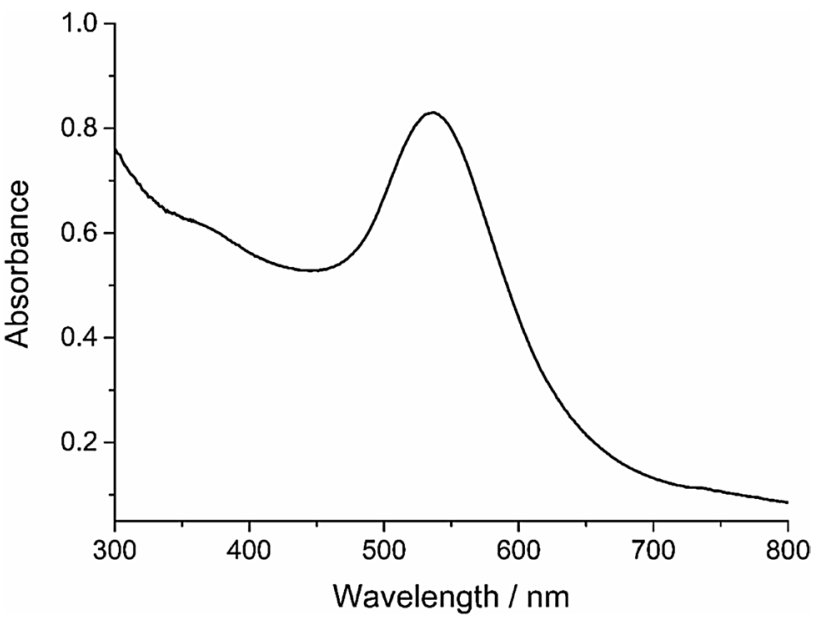

Fig. 8 Absorption spectra of the NNP aqueous solution

The characterization of the NNP, whose main characteristic is that they do not have a stabilizing agent, was carried out using UV-Vis absorption, SEM images, EDS, and DLS analysis. In this way, the UV-Vis spectrum (see Fig. 8) of NNPs shows a SPA band at $535 \mathrm{~nm}$, corroborating the presence of spherical AuNPs. It has been reported that spherical AuNPs have a strong absorption around $520 \mathrm{~nm}$ and that the position of this band can shift depending on the size of the nanoparticle, e.g., for AuNPs dimensions between 5 and $100 \mathrm{~nm}$, the corresponding absorption bands are between 515 and $572 \mathrm{~nm}$. [26] While the characterization by SEM (see Fig. 2c) allows observing some particles with spherical shapes, although in general agglomerations are observed. EDS analysis of NNP shows the characteristic bands of Au
Fig. 7 Comparison between (a) absorption spectra of P6CAAuNPs aqueous solution and (b) emission spectra of free P6CA in water, $\lambda_{\mathrm{ex}}=364 \mathrm{~nm}$
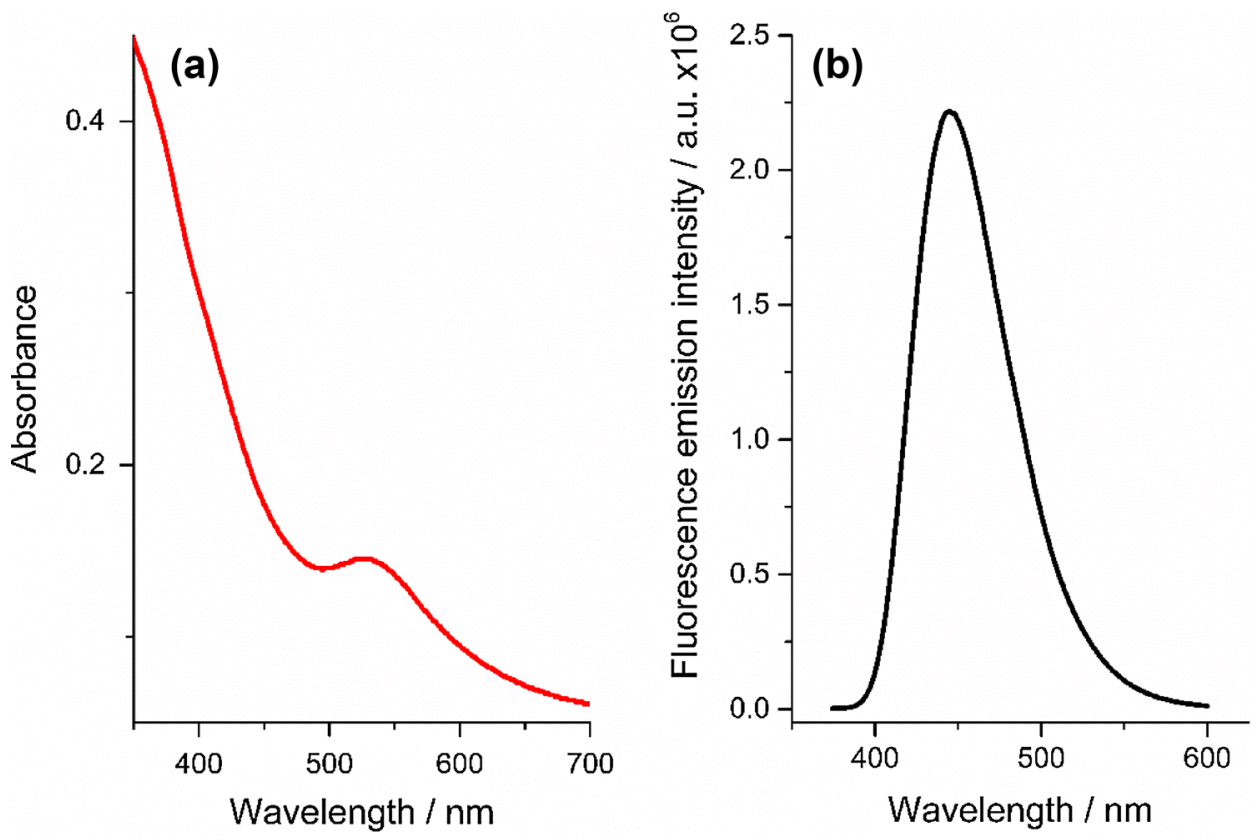
(see Fig. 4b), which forms the core of NNP. Furthermore, the signals that correspond to $\mathrm{C}$ and $\mathrm{O}$ elements can be attributed to the carbon ribbon to secure the sample holder.

We observed by DLS analysis the values of $\mathrm{Z}$ average size $(112.0 \pm 11.4 \mathrm{~nm})$ and PDI $(0.42 \pm 0.02)$ for NNP. The NNP sizes histogram (Fig. 3b) significant particle populations, of which the smallest particle group is around $25 \mathrm{~nm}$. Furthermore, the average $\mathrm{Z}$ potential of NNP was $0 \pm 0.19 \mathrm{mV}$. This result indicates that the surface charge density of particles is very low, similar to that obtained for the P6CA-AuNP.

P6CA-AuNP were not toxic to HeLa cells at any of the four concentrations tested (see Fig. 9). Statistical analysis did not show significant differences between the percent cell viability of treated versus untreated cells. Following irradiation with the laser diode, P6CA-AuNP treated cells showed decreased viability in a dose-dependent manner. The

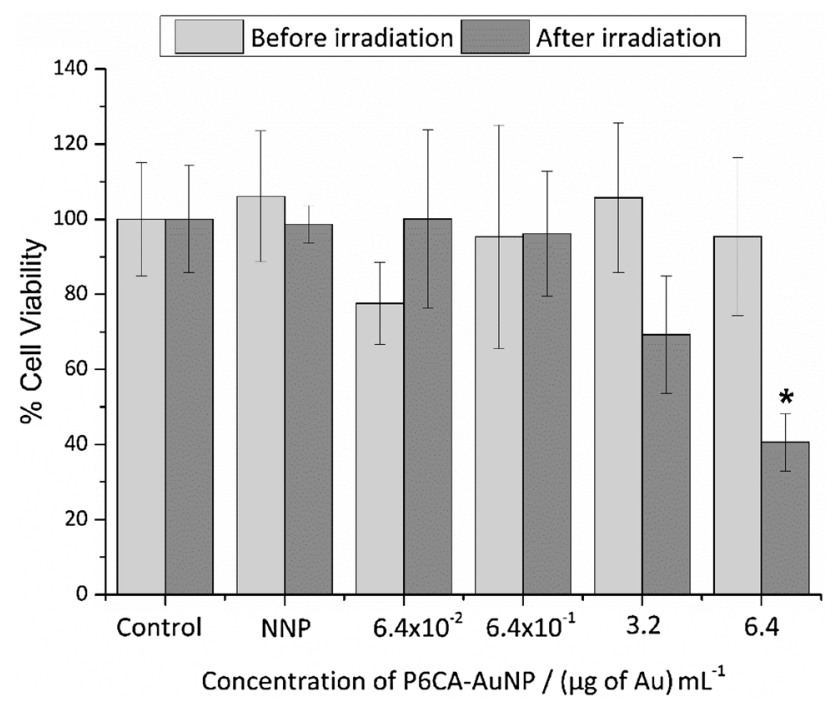

Fig. 9 Effect of P6CA-AuNP on the viability of HeLa cells with NIR irradiation. Control: cells not treated with nanoparticles. NNP: cells treated with naked AuNPs at $(6.4 \mu \mathrm{g}$ of $\mathrm{Au} / \mathrm{mL})$. *A Statistically significant difference compared to non-irradiated cells and treated with the same concentration of nanoparticles, $p<0.05$
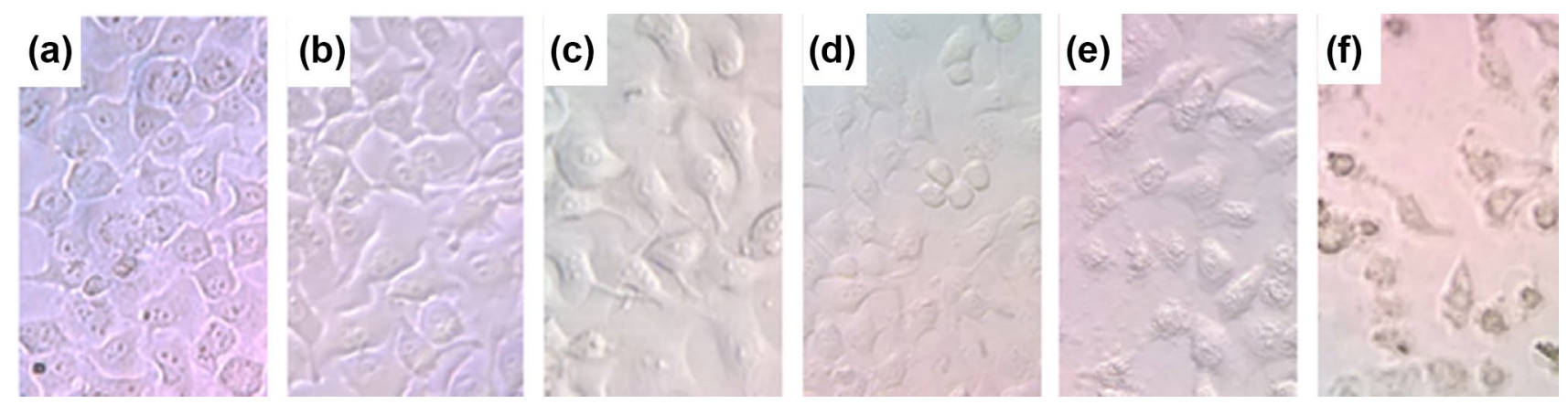

Fig. 10 Unirradiated (a) and irradiated (b) control group; HeLa cells treated with P6CA-AuNP at $6.4 \times 10^{-2} \mu \mathrm{g} / \mathrm{mL}(\mathbf{c}), 6.4 \times 10^{-1} \mu \mathrm{g} / \mathrm{mL}(\mathbf{d})$, $3.2 \mu \mathrm{g} / \mathrm{mL}$ (e) and $6.4 \mu \mathrm{g} / \mathrm{mL}$ (f) after NIR irradiation for 5 min observed by optical inverted microscope views $\times 40$ 

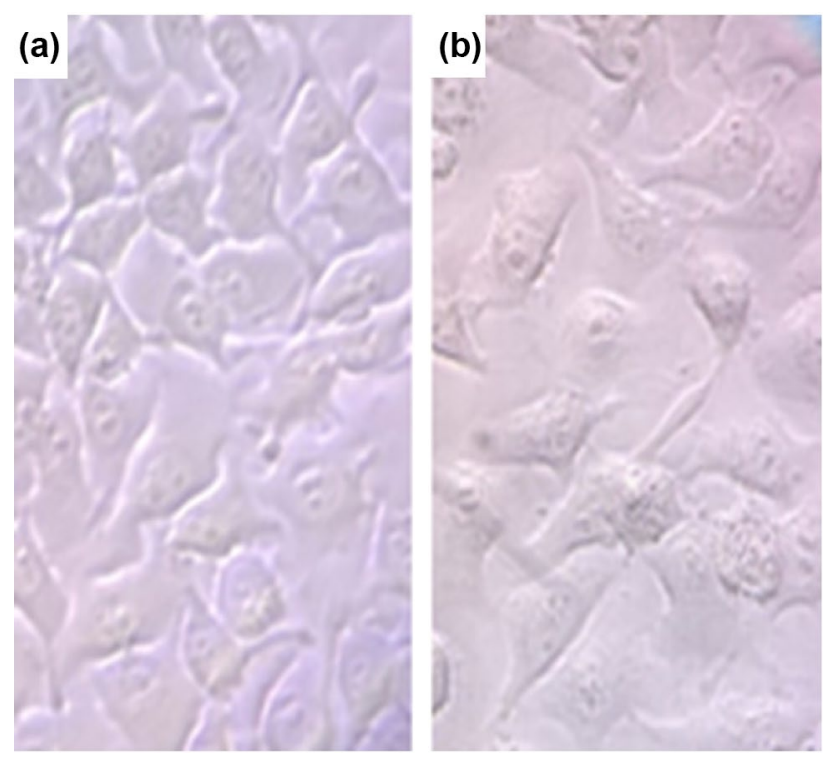

Fig. 11 Irradiated control group (a) and HeLa cells treated with NNP (b) after NIR irradiation for $5 \mathrm{~min}$ observed by optical microscope views $\times 40$

Chithrani et al. have reported that HeLa cells internalize in higher proportion AuNPs of sizes of $50 \mathrm{~nm}$ compared to AuNPs of 14 and $100 \mathrm{~nm}$ [36]. They also found that the internalization was of a few AuNPs for all NP sizes tested. In this work, the NNP did not generate the focused heating required to cause cytotoxicity, possibly due to low internalization.

Besides, results could indicate that the pterin molecules facilitate the P6CA-AuNP internalization since it has been reported that folate binds to the folate receptor through its pterin group [23]. In general, it is known that the cellular internalization mechanism of AuNPs depends on their size, shape, and surface characteristics and the type of cell line used [37]. For example, Abanese et al. found that the uptake rate of aggregated AuNPs is high in melanoma MDA-MB 435 cells, unlike HeLa and A549 cells, for which they observed reduced internalization [38]. Cells can activate different endocytosis pathways (receptor-, caveolae-, nonclathrin- and non-caveolin-mediated) or other transport pathways to enter AuNPs, and it is for this reason that different cell lines can more or less internalize amount of the same type of AuNPs [37]. In particular, HeLa and A549 cells internalize AuNP aggregates through receptor-mediated endocytosis, while MDA-MB435 employs mechanisms other than receptor-mediated [38]. In this sense, it is likely that P6CA-AuNP prepared here are targeted to folate receptors of HeLa cells since P6CA-AuNP also form aggregates as can be seen in the SEM images in Fig. 2a and results by DLS in Fig. 3a (where two groups of large particles can be seen around 330 and $4975 \mathrm{~nm}$ ).
It is essential to mention, another mechanism as penetration or adhesion may be involved. The penetration process occurs when a small particle $(<20 \mathrm{~nm})$, [39], it can slip through the cell membrane [24]. On the other hand, in adhesion, the particle fails to cross the cell membrane, remaining on the surface $[24,39]$. In our case, the size distribution of P6CA-AuNP obtained by DLS does not show that particles with sizes below $20 \mathrm{~nm}$ are present, unlike the NNP, where particles of these dimensions are observed.

\section{Conclusions}

This work shows a simple synthesis of AuNPs functionalized with P6CA utilizing UV radiation. Additionally, the nanoconjugate is surfactants (or another organic composes) free. Thus, P6CA-AuNP were biocompatible with HeLa cells and showed significant cytotoxicity results after irradiation. The reduction of cell viability following NIR irradiation was dependent on the dose of the P6CA-AuNP nanoparticle used.

This paper reports for the first time that P6CA can function as an agonist of FA in the internalization of AuNPs into the HeLa cells, which are known to overexpress folate receptors.

Results in the photothermal therapy of HeLa cells with this nanoconjugate are promising, showing a statistically significant reduction in the cell viability up to $40.6 \%$. This result of reduction of cell viability after irradiation indicates that internalization of AuNPs was achieved. Then, folate receptors of HeLa cells interact with pterin P6CA, and the P6CA-AuNP conjugate is internalized by endocytosis.

Acknowledgements The authors would like to acknowledge the financial support for this study by the Universidad Industrial de SantanderUIS (Project DIEF 2320) and the teams of Laboratorio de Microscopia for SEM images and Laboratorio de espectroscopia Atómica y Molecular for ATR-FTIR spectra (Parque Tecnológico Guatiguará of Universidad Industrial de Santander, UIS).

\section{Declarations}

Conflict of interest There are no conflicts to declare.

\section{References}

1. Huang, W. C., \& Chen, Y. C. (2008). Photochemical synthesis of polygonal gold nanoparticles. Journal of Nanoparticle Research, 10(4), 697-702. https://doi.org/10.1007/s11051-007-9293-8

2. Dong, S., Tang, C., Zhou, H., \& Zhao, H. (2004). Photochemical synthesis of gold nanoparticles by the sunlight radiation using a seeding approach. Gold Bulletin, 37(3-4), 187-195. https://doi. org/10.1007/BF03215212 
3. Ahmed, M., \& Narain, R. (2010). Rapid synthesis of gold nanorods using a one-step photochemical strategy. Langmuir, 26(23), 18392-18399. https://doi.org/10.1021/la103339g

4. Rodríguez-Torres, M. P., Díaz-Torres, L. A., \& Romero-Servin, S. (2014). Heparin assisted photochemical synthesis of gold nanoparticles and their performance as SERS substrates. International Journal of Molecular Sciences, 15(10), 19239-19252. https://doi.org/10.3390/ijms151019239

5. Lee, K., Lee, H., Bae, K. H., \& Park, T. G. (2010). Heparin immobilized gold nanoparticles for targeted detection and apoptotic death of metastatic cancer cells. Biomaterials, 31(25), 6530-6536. https://doi.org/10.1016/j.biomaterials.2010.04.046

6. Sega, E. I., \& Low, P. S. (2008). Tumor detection using folate receptor-targeted imaging agents. Cancer and Metastasis Reviews, 27(4), 655-664. https://doi.org/10.1007/ s10555-008-9155-6

7. Duan, L., \& Zhao, Y. (2018). Selective binding of folic acid and derivatives by imprinted nanoparticle receptors in water. Bioconjugate Chemistry, 29(4), 1438-1445. https://doi.org/10.1021/acs. bioconjchem.8b00121

8. Boca-Farcau, S., Potara, M., Simon, T., Juhem, A., Baldeck, P., \& Astilean, S. (2014). Folic acid-conjugated, SERS-labeled silver nanotriangles for multimodal detection and targeted photothermal treatment on human ovarian cancer cells. Molecular Pharmaceutics, 11(2), 391-399. https://doi.org/10.1021/mp400300m Epub 2013 Dec 12 PMID: 24304361.

9. Siwowska, K., Schmid, R. M., Cohrs, S., Schibli, R., \& Müller, C. (2017). Folate receptor-positive gynecological cancer cells: In vitro and in vivo characterization. Pharmaceuticals, 10(3), 72. https://doi.org/10.3390/ph10030072

10. Wang, L., Wu, C., Qiao, L., Yu, W., Guo, Q., Zhao, M., Yang, G., Zhao, H., \& Lou, J. (2017). Clinical significance of folate receptor-positive circulating tumor cells detected by ligand-targeted polymerase chain reaction in lung cancer. Journal of Cancer, $8(1)$, 104-110. https://doi.org/10.7150/jca.16856

11. Chen, Y., Cao, W., Zhou, J., Pidhatika, B., Xiong, B., Huang, L., Tian, Q., Shu, Y., Wen, W., Hsing, I., \& Wu, H. (2015). Poly(1 -lysine)- graft -folic acid-coupled poly(2-methyl-2-oxazoline) (PLL- g -PMOXA- c-FA): A bioactive copolymer for specific targeting to folate receptor-positive cancer cells. ACS Applied Materials and Interfaces, 7(4), 2919-2930. https://doi.org/10. 1021/am508399w

12. Liu, Q., Xu, S., Niu, C., Li, M., He, D., Lu, Z., Ma, L., Na, N., Huang, F., Jiang, H., \& Ouyang, J. (2015). Distinguish cancer cells based on targeting turn-on fluorescence imaging by folate functionalized green emitting carbon dots. Biosensors and Bioelectronics, 64, 119-125. https://doi.org/10.1016/j.bios.2014.08. 052

13. Qin, X. C., Guo, Z. Y., Liu, Z. M., Zhang, W., Wan, M. M., \& Yang, B. W. (2013). Folic acid-conjugated graphene oxide for cancer targeted chemo-photothermal therapy. Journal of Photochemistry and Photobiology, B: Biology, 120, 156-162. https:// doi.org/10.1016/j.jphotobiol.2012.12.005

14. Xiao, Z., Ji, C., Shi, J., Pridgen, E. M., Frieder, J., Wu, J., \& Farokhzad, O. C. (2012). DNA self-assembly of targeted nearinfrared-responsive gold nanoparticles for cancer thermo-chemotherapy. Angewandte Chemie, 51(47), 11853-11857. https://doi. org/10.1002/anie.201204018

15. Bertel, L., Méndez, S. C., \& Martínez, F. (2018). Use in vitro of gold nanoparticles functionalized with folic acid as a photothermal agent on treatment of HeLa cells. Journal Mex Chemical Society, 62(1), 1-13. https://doi.org/10.29356/jmcs.v62i1.385

16. Bellotti, E., Cascone, M. G., Barbani, N., Rossin, D., Rastaldo, R., Giachino, C., \& Cristallini, C. (2021). Targeting cancer cells overexpressing folate receptors with new terpolymer-based nanocapsules: Toward a novel targeted DNA delivery system for cancer therapy. Biomedicines, 9(9), 1275. https://doi.org/10.3390/biome dicines 9091275

17. Tsai, S.-W., Liaw, J.-W., Hsu, F.-Y., Chen, Y.-Y., Lyu, M.-J., \& Yeh, M.-H. (2008). Surface-modified gold nanoparticles with folic acid as optical probes for cellular imaging. Sensors, $8(10)$, 6660-6673. https://doi.org/10.3390/s8106660

18. Li, G., Li, D., Zhang, L., Zhai, J., \& Wang, E. (2009). One-step synthesis of folic acid protected gold nanoparticles and their receptor-mediated intracellular uptake. Chemistry A European Journal, 15(38), 9868-9873. https://doi.org/10.1002/chem.20090 0914

19. Zhang, Z., Jia, J., Lai, Y., Ma, Y., Weng, J., \& Sun, L. (2010). Conjugating folic acid to gold nanoparticles through glutathione for targeting and detecting cancer cells. Bioorganic \& Medicinal Chemistry, 18(15), 5528-5534. https://doi.org/10.1016/j.bmc. 2010.06.045

20. Zhang, H., Chen, H. J., Du, X., \& Wen, D. (2014). Photothermal conversion characteristics of gold nanoparticle dispersions. Solar Energy, 100, 141-147. https://doi.org/10.1016/j.solener.2013.12. 004

21. Mendes, R., Pedrosa, P., Lima, J. C., Fernandes, A. R., \& Baptista, P. V. (2017). Photothermal enhancement of chemotherapy in breast cancer by visible irradiation of Gold Nanoparticles. Scientific Reports, 7(1), 10872. https://doi.org/10.1038/ s41598-017-11491-8

22. Tong, L., Zhao, Y., Huff, T. B., Hansen, M. N., Wei, A., \& Cheng, J.-X. (2007). Gold nanorods mediate tumor cell death by compromising membrane integrity. Advanced Materials, 19, 3136-3141. https://doi.org/10.1002/adma.200701974

23. Chen, C., Ke, J., Edward Zhou, X., Yi, W., Brunzelle, J. S., Li, J., Yong, E. L., Xu, H. E., \& Melcher, K. (2013). Structural basis for molecular recognition of folic acid by folate receptors. Nature, 500(7463), 486-489. https://doi.org/10.1038/nature12327

24. Blach, D., Alves De Souza, C. E., Méndez, S. C., \& Martínez, F. O. (2021). Conjugated anisotropic gold nanoparticles through pterin derivatives for a selective plasmonic photothermal therapy: In vitro studies in HeLa and normal human endocervical cells. Gold Bulletin, 54, 9-23. https://doi.org/10.1007/ s13404-020-00288-9

25. Castillo, J., Bertel, L., Páez-Mozo, E., \& Martínez, F. (2013). Photochemical synthesis of the bioconjugate folic acid-gold nanoparticles. Nanomaterials and Nanotechnology, 3, 1-6. https://doi. org/10.5772/57144

26. Mosmann, T. (1983). Rapid colorimetric assay for cellular growth and survival: Application to proliferation and cytotoxicity assays. Journal of immunological methods, 65(1-2), 55-63. https://doi. org/10.1016/0022-1759(83)90303-4G

27. Nealon, G. L., Donnio, B., Greget, R., Kappler, J. P., Terazzi, E., \& Gallani, J. L. (2012). Magnetism in gold nanoparticles. Nanoscale, 4(17), 5244-5258. https://doi.org/10.1039/c2nr30640a

28. Eaton, P., Quaresma, P., Soares, C., Neves, C., de Almeida, M. P., Pereira, E., \& West, P. (2017). A direct comparison of experimental methods to measure dimensions of synthetic nanoparticles. Ultramicroscopy, 182, 179-190. https://doi.org/10.1016/j.ultra mic.2017.07.001

29. Kowalczyk, B., Lagzi, I., \& Grzybowski, B. A. (2011). Nanoseparations: Strategies for size and/or shape-selective purification of nanoparticles. Current Opinion in Colloid and Interface Science, 16(2), 135-148. https://doi.org/10.1016/j.cocis.2011.01.004

30. Qin, Z., Wang, Y., Randrianalisoa, J., Raeesi, V., Chan, W. C. W., Lipiński, W., \& Bischof, J. C. (2016). Quantitative comparison of photothermal heat generation between gold nanospheres and nanorods. Science and Reports, 6, 29836. https://doi.org/10.1038/ srep29836

31. Wangoo, N., Bhasin, K. K., Mehta, S. K., \& Suri, C. R. (2008). Synthesis and capping of water-dispersed gold nanoparticles by 
an amino acid: Bioconjugation and binding studies. Journal of Colloid and Interface Science, 323(2), 247-254. https://doi.org/ 10.1016/j.jcis.2008.04.043

32. Kang, K. A., Wang, J., Jasinski, J. B., \& Achilefu, S. (2011). Fluorescence manipulation by gold nanoparticles: From complete quenching to extensive enhancement. Journal of Nanobiotechnology, 9, 1-13. https://doi.org/10.1186/1477-3155-9-16

33. Chhabra, R., Sharma, J., Wang, H., Zou, S., Lin, S., Yan, H., Lindsay, S., \& Liu, Y. (2009). Distance-dependent interactions between gold nanoparticles and fluorescent molecules with DNA as tunable spacers. Nanotechnology, 20, 48. https://doi.org/10. 1088/0957-4484/20/48/485201

34. Avila, R., Tamariz, E., Medina-Villalobos, N., Andilla, J., Marsal, M., \& Loza-Alvarez, P. (2018). Effects of near infrared focused laser on the fluorescence of labelled cell membrane. Science and Reports, 8(1), 17674. https://doi.org/10.1038/s41598-018-36010-1

35. Vines, J. B., Yoon, J. H., Ryu, N. E., Lim, D. J., \& Park, H. (2019). Gold nanoparticles for photothermal cancer therapy. Frontiers in Chemistry, 7, 1-16. https://doi.org/10.3389/fchem.2019.00167
36. Chithrani, B. D., Ghazani, A. A., \& Chan, W. C. (2006). Determining the size and shape dependence of gold nanoparticle uptake into mammalian cells. Nano Letters, 6(4), 662-668. https://doi. org/10.1021/n1052396o

37. Panzarini, E., Mariano, S., Carata, E., Mura, F., Rossi, M., \& Dini, L. (2018). Intracellular transport of silver and gold nanoparticles and biological responses: An update. International Journal of Molecular Sciences, 19, 5. https://doi.org/10.3390/ijms19051305

38. Albanese, A., \& Chan, W. (2011). Effect of gold nanoparticle aggregation on cell uptake and toxicity. ACS Nano, 5, 5478-5489. https://doi.org/10.1021/nn2007496

39. Nakamura, H., \& Watano, S. (2018). Direct permeation of nanoparticles across cell membrane: A review. KONA Powder and Particle Journal, 2018(35), 49-65. https://doi.org/10.14356/kona. 2018011

\section{Authors and Affiliations}

\section{Linda Bertel $^{1,2} \cdot$ Stelia Carolina Mendez-Sanchez ${ }^{3} \cdot$ Fernando Martínez-Ortega $^{1,2}$ (D)}

1 Centro de Investigaciones en Catálisis, Universidad Industrial de Santander, Sede Guatiguará UIS, Km 2 vía Refugio, Piedecuesta, Colombia

2 Centro de Investigación Científica Y Tecnológica en Materiales Y Nanociencias (CMN), Universidad Industrial de Santander, Sede Guatiguará UIS, Km 2 vía Refugio, Piedecuesta, Colombia
3 Grupo de Investigación en Bioquímica Y Microbiología GIBIM, Universidad Industrial de Santander, Sede Guatiguará UIS, Km 2 vía Refugio, Piedecuesta, Colombia 